\title{
American Pediatric Society Presidential Address 2001: Opportunity and Response
}

\author{
THOMAS F. BOAT \\ Department of Pediatrics, University of Cincinnati College of Medicine and Children's Hospital Medical Center, \\ Cincinnati, Ohio 45229
}

It has been an honor to serve as President of the APS for the past year. In addition to joint sponsorship of this meeting and selection of the Howland Awardee, the APS has played leadership roles in planning and advocacy for research and training issues in academic pediatrics, issues that affect all of us on a daily basis.

No question about it, we are fortunate to be academic pediatricians in a time of unparalleled opportunity to advance child health care. We have many exciting opportunities to contribute to an explosion of information about biologic processes that regulate growth, organogenesis, and the maturation of physiologic functions, as well as the genetic and environmental basis for disordered development. In addition to Developmental Biology, other areas of science have opened doors of understanding that are key for advances in all facets of pediatric medicine. Secondly, we are fortunate to be able to translate more and more of this fundamental information into new diagnostic, therapeutic, and preventive strategies that will enhance child health and well-being. As the result of supportive positions by the National Institutes of Health and FDA, opportunities for interventional research involving children abound. Never before have we had the array of tools to design, implement, and report clinical trials that are capable of generating definitive outcomes data. Never before have we understood so clearly what is possible in the realm of prevention and health promotion that targets children.

Thirdly, we can assess the quality of our health services delivery systems in new ways that should improve accessibility, safety, cost effectiveness, and outcomes of pediatric care. Assessment of clinical effectiveness has become an academic endeavor for increasing numbers of pediatric faculty, one that fortunately has directed the spotlight onto family and patient satisfaction. As an aside, our responsiveness to their needs must be a top priority if academic pediatrics is to remain relevant in the provision of health care to children.

\footnotetext{
Received July 27, 2001; Accepted August 28, 2001.

Correspondence: Thomas F. Boat, MD, Children's Hospital Medical Center, 3333 Burnet Avenue, Cincinnati, OH 45229; e-mail: thomas.boat@chmcc.org

Presented at the 2001 Annual Meeting of the Pediatric Academic Societies, Baltimore,
} MD.

DOI: 10.1023/01.PDR.0000015610.90138.D3
There are a number of reasons for greater research opportunities today. I will briefly mention two: enhanced research funding, and an array of technological advances.

An obvious impetus for rapid bioscientific advances has been an expanding public investment in research through the National Institutes of Health (Fig. 1). Extramural National Institutes of Health funding has grown rapidly in the last 2 fiscal years $(1999,2000)$ and supports more clinical as well as biomedical research. Paylines for proposals have doubled since the mid-1990s. If stated bipartisan intentions become reality, the National Institutes of Health budget will double in the 5 years from 1998-2000. We face an extraordinary opportunity.

The Agency for Healthcare Research and Quality (AHRQ), likewise, is distributing more extramural support dollars, albeit on a smaller scale (Fig. 2). Although there are no final figures, their fiscal year 2001 distribution is on track to exceed \$200 million, which would represent a doubling in the 3 years since 1998. Another opportunity.

The research and development expenditures of industry related to medical products have also been increasing rapidly. R\&D expenditures of pharmaceutical companies alone exceeded the total National Institutes of Health budget in 1999 (Table 1). According to the Industrial Research Institute, industry investment in R\&D increased $12 \%$ on average for each of the $5 \mathrm{y}$ between 1995 and 1999. Industry is turning more frequently to the academic sector to carry out their product-oriented basic as well as clinical studies. Industry needs us for access to the brightest, most creative scientists. In addition, they need our patient populations and clinical expertise. We need industry to help us move concepts and technologies into practice. This partnership, if entered into very thoughtfully, will advantage children's health for years to come. A largely untapped opportunity.

A second reason for unprecedented research opportunities is a series of new, and what has come to be known as enabling, technologies. These technologies allow us to ask questions that were unapproachable a few short years ago, and have collapsed the experimental time frame, in some cases, from years to days. They include:

1. Human and model organism gene maps, based on sequencing of the respective genomes, now a part of our scientific database. 


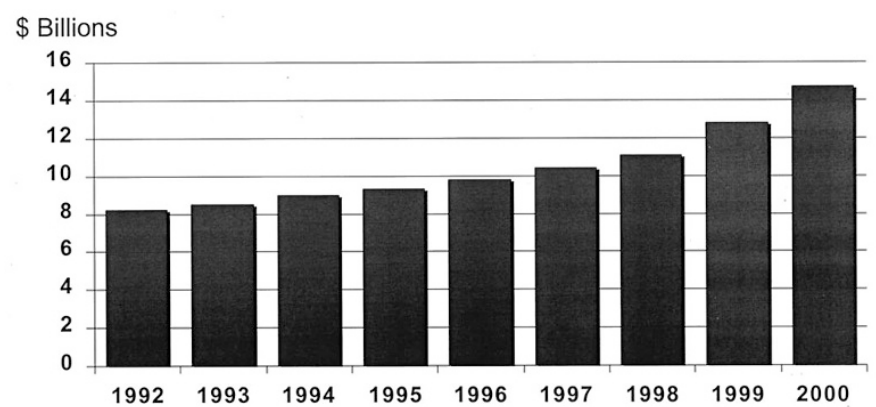

Figure 1. Extramural National Institutes of Health funding in all categories, fiscal years 1992-2000. Data source: Website, https://silk.nih.gov/public/cbz2zoz.@ www.trends00.cl32a.dsncc

2. Techniques, mathematical as well as biologic, to identify single or multiple genes that are responsible for human traits, including those modulating susceptibility to disease, environmental insults or drug effects.

3. Expression profiling of hundreds of genes as a function of specific conditions, physiologic or pathologic.

4. Mass spectrometry to size and determine the sequence of peptides in a high through-put fashion.

5. NMR and crystallographic techniques to determine and plan modifications of the structure of complex molecules.

6. Genetically modified experimental animals and timed expression of modified genes to mimic human congenital disorders.

7. Imaging techniques to assess not only structure, but function of here-to-fore largely inaccessible organs.

8. Perhaps most importantly, our Bioinformatics colleagues can capture and analyze complex and voluminous data, such as those generated by gene expression arrays, or large clinical databases. A few short years ago, these analyses were formidable if not impossible.

Pediatrics will contribute to rapid biomedical advances to the extent that investigators in our departments have access to these technologies for child health research. Most pediatric departments do not have the resources to establish all, or even some, of these core capabilities. Collaborative approaches will be needed to ensure that the pediatric contribution to medical research remains at the cutting edge.

Opportunity is indeed unprecedented. But opportunity begs for response, an equivalently unprecedented response. How prepared are we, as the keepers of child health care innovation, to seize this opportunity? I suggest three agendas for academic pediatrics, agendas that if successfully addressed should allow us to participate fully:

1. How we conduct research involving children.

2. How successful we will be in competing for resources to support our research efforts

3. Whether we will train a pediatric workforce capable of seizing tomorrow's opportunities.

\section{The Conduct of Patient-Focused Research}

The media are raising huge questions about the conduct of research involving children. It would be tragic for children if

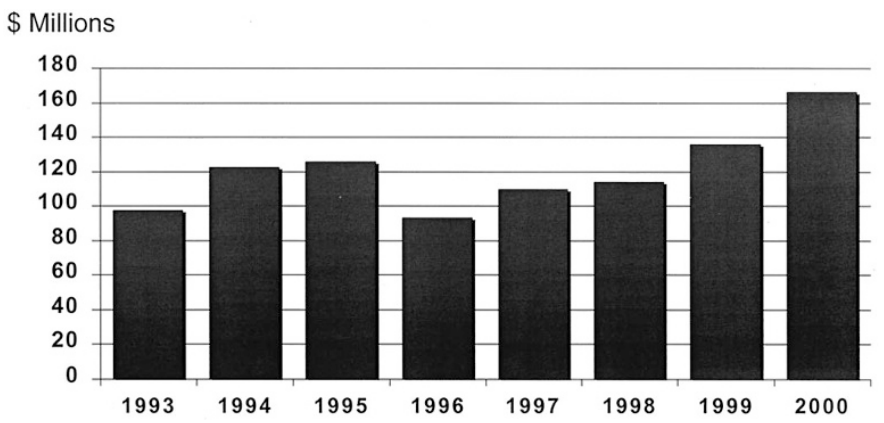

Figure 2. Extramural funding by the Agency for Health Research and Quality, fiscal years 1993-2000. Data courtesy of Lisa Simpson.

Table 1. Biomedical R\&D Investment-1999

\begin{tabular}{lc}
\hline & Billions \\
\hline NIH (total budget) & 15.7 \\
& \\
Industry* & 19.9 \\
Drugs and medicines & 3.7 \\
Medical and optical equipment & \\
\hline
\end{tabular}

* Data from the Industrial Research Institute.

they were excluded from translational investigation. To preclude this outcome, it is imperative that we conduct studies with children so as to protect their interests and well being, and assure the public that we are free of arrangements that could undermine this objective. There is a movement toward more explicit codes of conduct in human research. Whatever the cost or the inconvenience, we should be defining our own departmental rules in anticipation of federal regulations, and effectively monitoring compliance. We must educate and perhaps credential Pediatric faculty and staff who are conducting childoriented research.

\section{Resources to Support Pediatric Research}

While some Children's Hospitals and Pediatric Departments do invest in research and development, either from earnings on operations or philanthropy, most Pediatric Programs are largely dependent on extramural funding to support research efforts. Therefore our future depends on how well we advocate for dollars to support child health research, and perhaps more importantly, on how successful we are in competing for dollars from public and private funding sources. How are we faring?

One success story has been Pediatric funding through the Agency for Health Research and Quality (AHRQ). In 3 years, AHRQ funding for Children's Health Care Research has increased 2.5-fold (Fig. 3), well ahead of total budget increases for the agency. Child Health Services research garnered an $18 \%$ share of the AHRQ budget in the past fiscal year, up from approximately $12 \%$ in the mid-1990s. This speaks well for the efforts of our faculties.

National Institutes of Health dollars also are flowing to our Pediatric Programs, both Children's Hospital and University based, in increasing amounts (Fig. 4). Growth of pediatric funding was slow in the mid-1990s, a time of low paylines, but has increased by $48 \%$ in the 3 years from 1997 to 2000 . During this time the extramural National Institutes of Health budget 


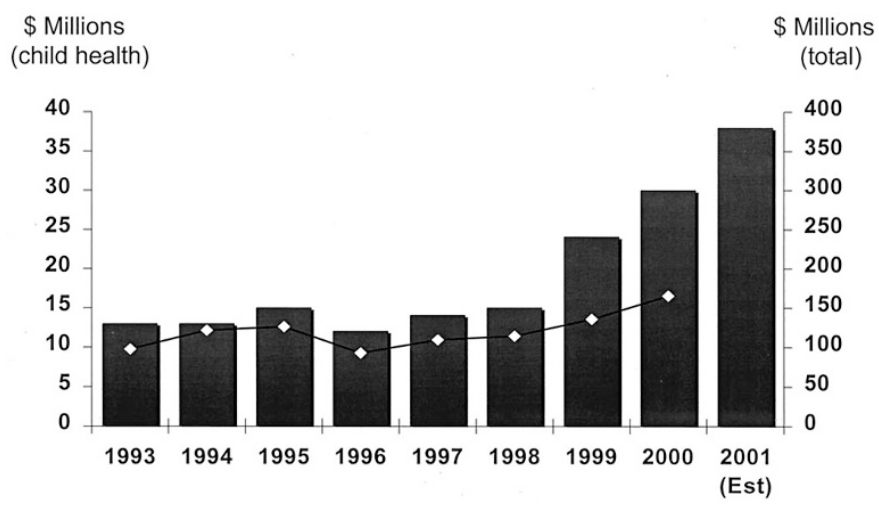

Figure 3. Growth in Agency for Health Research and Quality spending for children's health care research and dissemination (solid bars) compared with total extramural funding (-). Data courtesy of Lisa Simpson.

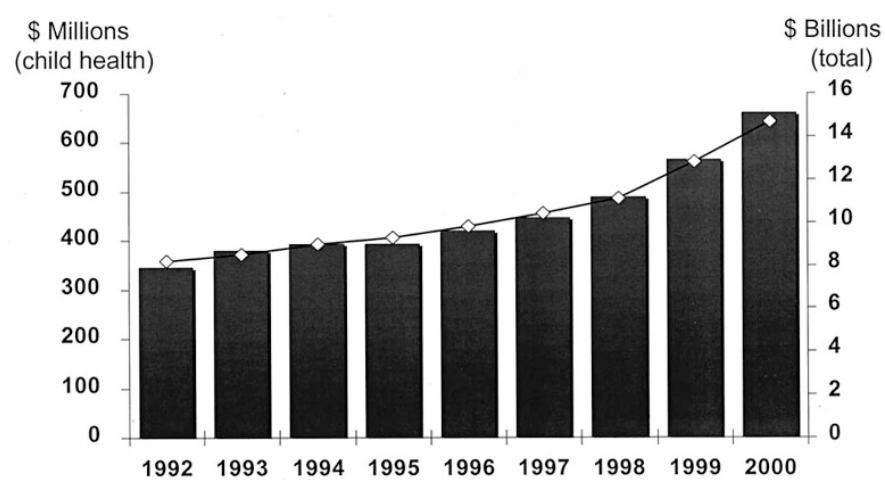

Figure 4. National Institutes of Health extramural funding by fiscal year of Pediatric Departments and Children's Hospitals (solid bars) compared with total extramural funding (-). Data source as in Fig. 1.

increased 38\%. Although, in the 9 years analyzed, Pediatric funding has almost doubled, Pediatric share of the National Institutes of Health extramural budget has improved only a few tenths of a percentage point. It was $4.2 \%$ in $1992,4.3 \%$ in 1996, and in 2000 was $4.5 \%$, suggesting that we are making, at best, very modest progress toward capturing a larger share of the growing National Institutes of Health budget.

Table 2 illustrates that our market share (4.5\%) compared with that of Medicine (14\%) or even Psychiatry (3.8\%) has changed little in the last 5 years. We must challenge ourselves to do better. Obtaining a more substantial appropriation for child health-related programs is one way to do better. Each of us individually, as well as the Academic Societies through our Public Policy efforts, should be tireless in making a compelling case for Pediatric research funding, based on opportunity for enhancement of life-long health. Achieving a higher rate of success for Pediatric proposals submitted to the National In-

Table 2. Total NIH extramural funding by department

\begin{tabular}{lcc}
\hline & \multicolumn{2}{c}{ Billions (\% of total) } \\
\cline { 2 - 3 } & \multicolumn{1}{c}{1996} & 2000 \\
\hline Medicine & $\$ 1.40(14.2)$ & $\$ 2.07(14.0)$ \\
Pediatrics & $0.42(4.3)$ & $0.65(4.5)$ \\
Psychiatry & $0.36(3.7)$ & $0.56(3.8)$ \\
Total NIH & 9.83 & 14.8 \\
\hline
\end{tabular}

stitutes of Health is another way to improve pediatric research funding. Pediatric Department success rates have risen from $21 \%$ in 1994 to $31 \%$ in 1999 (Table 3). However, we lag Medicine in particular, but also Psychiatry and all biomedical disciplines in aggregate by several percentage points. Strategies to increase our competitiveness must be at the forefront of our thoughts. Research leadership in Pediatrics is key but in my opinion it is currently thin. Recruiting outstanding scientists from other disciplines into Pediatric Departments is a strategy that could provide a quick fix. Critical for the long run will be the training of a larger and better prepared generation of pediatric scientists.

Extramural support for research fellowships will be needed if we are to train more clinician scientists. What is the status of National Institutes of Health support for Pediatric training? In FY2000, 89 Institutional Training Grants totaling \$16.7 million were awarded to Pediatric Departments and Children's Hospitals, representing $16 \%$ of all National Institutes of Health T32 award dollars (Table 4). Only 63 trainees in Pediatric Departments and Children's Hospitals were funded by F32 (individual NRSA) awards, totaling a paltry $\$ 2.3$ million and $7.5 \%$ of all F32 award dollars. Surprisingly, $67 \%$ and $45 \%$ of all T32 and F32 proposals were funded by National Institutes of Health last year. We are not submitting enough applications to justify appropriation of more National Institutes of Health training dollars, even though this support category has been flat for years. We will need much more support from this mechanism if we are to successfully train a larger number of physician scientists. The Future of Pediatric Education II recommendations include National Institutes of Health or other federal agency funding to support all fellowship research training (1). We are not close to hitting this target. What should we do?

For starters, our strategy should include more active pursuit of National Institutes of Health support for our fellows. As we ramp up the demand, we should then advocate for more National Institutes of Health training dollars. Meanwhile, we should vigorously seek alternative sources of training dollars.

\section{Training}

Several of my predecessors on this podium have pursued the theme that pediatric training does not encourage or promote successful academic pediatric careers (2-4). I join that chorus,

Table 3. Success rates (\%) for NIH research project applications

\begin{tabular}{llll}
\hline & 1994 & 1996 & 1999 \\
\hline Pediatrics (No Data for Children's Hospitals) & 21.2 & 23.1 & 31.1 \\
Medicine & 24.0 & 28.7 & 35.4 \\
Psychiatry & 26.8 & 27.3 & 32.1 \\
All departments & 25.7 & 28.8 & 33.9 \\
\hline
\end{tabular}

Table 4. FY 2000 NIH training grants to pediatric departments and children's hospitals

\begin{tabular}{lccc}
\hline \multicolumn{1}{c}{ Awards } & Number & $\begin{array}{c}\text { Dollars Awarded } \\
\text { (millions) }\end{array}$ & $\begin{array}{c}\text { Success Rate } \\
\text { (all applications) }\end{array}$ \\
\hline T32 (institutional) & 89 & 16.7 & $67 \%$ \\
F32 (individual) & 63 & 2.3 & $45 \%$ \\
\hline
\end{tabular}


and offer specific recommendations, with the hope that sometime soon, words will translate into action on the part of organized pediatrics. My recommendations target recruitment of fellows, and the introduction of more flexible curricula for fellowship training.

An important step for enhancing recruitment is the removal of barriers to the consideration of fellowship training by residents. In my opinion, the most formidable barrier in the year 2001 is economic. The average student entering residency has incurred indebtedness of $\$ 95,000$ according to the latest AAMC figures. Interest becomes due on completion of residency, at an average annual cost of about $\$ 10,000$ pretax dollars. This is a big bite out of the $\$ 40,000$ that first year fellows are paid. Should we be surprised that the percentage of residents opting for fellowship training has declined? It is imperative that we eliminate or reduce the indebtedness obstacle.

Several programs have begun to pay the interest on fellow's loans during training years. Better yet, the National Institutes of Health now has authorization to institute loan abatement, up to $\$ 35,000$ a year for 2 years for the trainees they support. Implementation is in the planning stages. For those eligible, loan abatement will be very helpful. To make this mechanism broadly available, Pediatrics must gear up to secure more National Institutes of Health training grants or become more creative in funding fellows from other National Institutes of Health awards.

A universal approach would be to pay fellows at a level that is more attractive. The National Institutes of Health will raise starting postdoctoral stipends to $\$ 45,000$ by 2004 . Several weeks ago at the Subspecialty Forum, sponsored by the Federation of Pediatric Organizations, the consensus was that PL 4 salaries should be $\$ 60,000-\$ 70,000$ (5). Of course, the challenge will be to identify the resources to raise fellowship salaries. Targets of our lobbying efforts should be not only federal and other agency funding sources, but also hospital and medical school leadership. For the latter, the argument can be made that training adequate numbers of fellows now will lower the costs of faculty recruitment in the future.

In addition to money issues, I believe that fellowships must be reconfigured to better target an array of career goals. Figure 5 shows our current one-size-fits all approach. Everyone does a year, in a few cases 18-24 months, of clinical training. Most Fellows do 2 years of research with a product (publication)

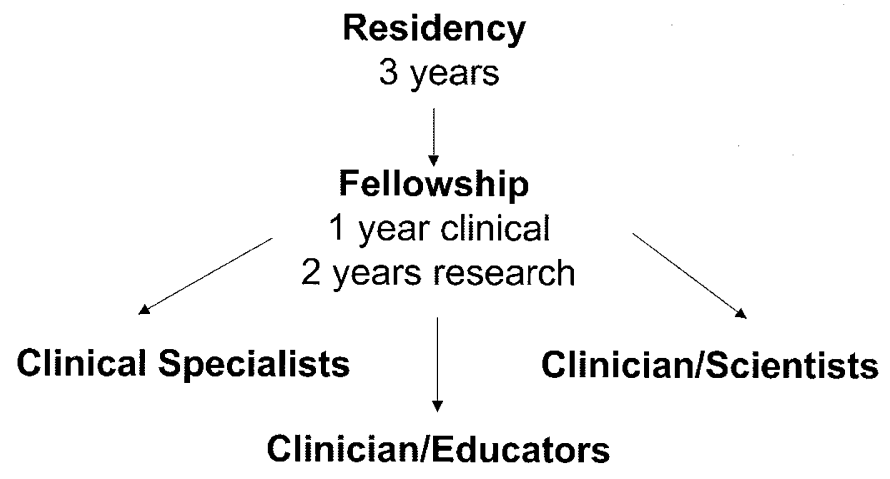

Figure 5. Current scheme for graduate medical education in Pediatrics. orientation to meet the American Board of Pediatrics' requirement for a "meaningful accomplishment in research." Many tackle a relatively trivial research project. The result is that we are neither training Fellows well for successful research careers, nor preparing Fellows optimally for clinically or educationally oriented academic careers.

An alternative approach is outlined in Fig. 6. Following residency, all fellows would do at least a year of clinical training. Beyond this core training, fellows could elect the remainder of their experience in one of three pathways: one for clinical specialists, one for clinician/educators, and one for clinician scientists.

With regard to the clinical specialist pathway, I pose an obvious question. Is there a need for academic faculty for whom being a master clinician is their priority? My answer is an emphatic yes. The complexity of subspecialty care in the molecular era is such that cutting edge approaches will reside, at least initially, in academic centers. Families are demanding a high level of disease-specific clinical expertise - not in gastroenterology, but in the care of liver diseases; not in endocrinology, but in diabetes; not in hematology/oncology, but in brain tumor expertise. Subspecialty referrals appear to be increasing in numbers and complexity (6), and are not likely to wane. If highly knowledgeable, responsive care is not available in our academic centers, patients will go elsewhere. This would have devastating effects on our ability to train and to carry out clinical research. Furthermore, there is a need for these individuals to participate in, not to direct, clinical research. They should contribute to patient databases, formulate clinically relevant questions, and organize patient enrollment. The last 2 years of fellowship for budding clinical specialists might require participation not only in clinical research efforts, but also in clinical effectiveness and quality activities. These individuals would also have the option to fit a year of third tier training into their curriculum. Examples would be a year of blood and marrow transplant or neuro-oncology training for hematology/ oncology fellows. They could also prepare for careers in health care management by obtaining MPH or even MBA degrees. Preparation of clinical specialists should occupy a minimum of three fellowship years.

A second pathway would target future clinician-educators. Our resident and fellowship programs are, in many cases, directed by individuals who have an interest in teaching, but no specific preparation in curriculum design, adult learning the-

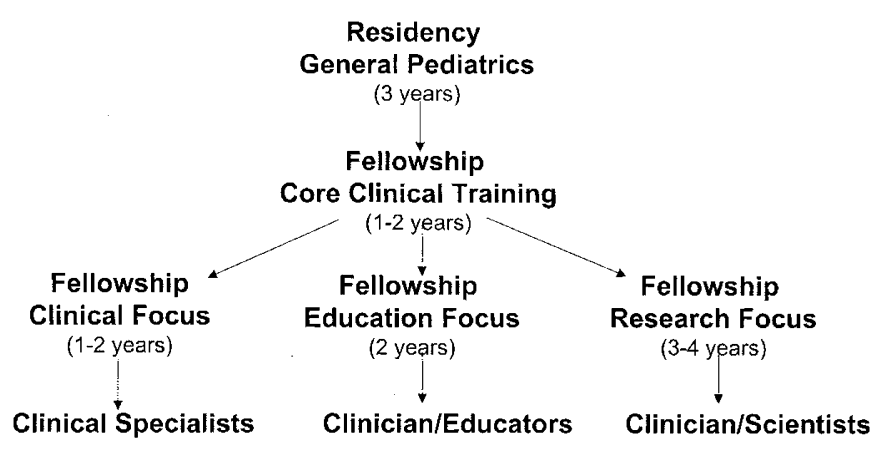

Figure 6. A proposed scheme for graduate medical education in Pediatrics. 
ory, evaluation of learners and teachers, and innovation within the educational process. Should we not train some academic faculty to take leadership roles in one of our most important efforts? Fellows who seek to be clinician educators might take graduate courses, perhaps leading to a degree in Medical Education. Some of these individuals hopefully will initiate research projects focused to education questions of importance to pediatrics.

Concerning the clinician/scientist pathway, fellowship training currently is nowhere near adequate to launch a research career. Most everyone would agree that, today, a serious investigator, whether clinical or basic, requires 3-5 years of mentored experience and protected time beyond fellowship. It would be less costly and wasteful of effort, if we revamped the training system to give future clinician scientists 3 to 4 years of focused research training, much like that of the Pediatric Scientist Development Program, before they are appointed to our faculties. In this way, we would have a better idea who will succeed before committing a faculty position, and trainees would have enough time to sort out their career plans based on research aptitude and productivity, before taking a faculty position. Three or 4 years of research training would allow time for graduate studies as well as mastery of research skills and approaches in laboratory based, clinical or health services research. Of course, if fellows extend their research experience in lieu of being appointed to transitional faculty positions, consideration must be given to even more steeply scaled salaries and fringe benefits.

I propose this fellowship training template (Fig. 6) with the hope that it will focus thinking, engender debate, and lead to changes that are in tune with current needs and demands. I also propose this template with the plea that we think flexibly about training. I have no desire to change training by substituting three cookie cutters for the one we now use.

As a final note, I would like to mention a special group of Pediatric trainees, those with a $\mathrm{PhD}$, or equivalent scientific training, as well as an MD. Last year I surveyed Departments of Pediatrics to determine how many residents were dually trained. The numbers were surprisingly high, between 68 and 82 in each class. They come to pediatrics with a rich experience in research. Sadly for the pediatric research agenda, many of them never enter academic or research careers. If the large majority chose academic careers, the incremental impact on our departments would be substantial. The American Board of Pediatrics just this year introduced a training option, the Pediatric Research Pathway, that has potential to keep these individuals engaged in research throughout graduate medical education, including up to eleven months in residency, and hopefully will encourage more of them to move seamlessly into research oriented fellowships and physician-scientist careers. The NICHD is planning a funding option for the research component of this residency pathway. I hope that Academic Pediatrics will take advantage of this and hopefully other new degrees of flexibility for training clinician scientists.

These innovations will, I believe, increasingly meet trainee and program needs and move us more assuredly to the goal that everyone desires, dynamic clinical care programs for children, fueled by the energy and creativity of our pediatric academic enterprise. We can achieve this goal if we pursue it with tenacity, vigor, and unwavering expectations for success.

\section{REFERENCES}

1. The future of pediatric education II: Organizing pediatric education to meet the needs of infants, children, adolescents, and young adults in the 21 st century. Pediatrics 105(suppl): 163-212

2. Rudolph AM 1994 American Pediatric Society Presidential Address 1994. Reflections on research: A call to arms. Pediatr Res 36:687-690

3. Feigin RD 1998 American Pediatric Society Presidential Address 1998: What is the future for academic pediatrics? Pediatr Res 44:958-963

4. Stockman JA, 1999 Issues Related to Subspecialty Education: Weasel Words in Action. J Pediatr 135:669-674

5. Jones MD, Boat TF, Stockman JA, Clark EB, Minaga-Miya K, Gilchrist GS, Colletti R, Winter HS 2001 Federation of Pediatric Organizations Subspecialty Forum. J Pediatr 139:487-493

6. Stoddard JJ, Cull WL, Jewett EAB, Brotherton SE, Mulvey HJ, Alden ER 2000 Providing subspecialty care: A workforce analysis. Pediatrics 106:1325-1333 